\title{
How Public Health Nurses Identify and Intervene in Child Maltreatment Based on the National Clinical Guideline
}

\author{
Paavilainen Eija, ${ }^{1}$ Helminen Mika, ${ }^{2}$ Flinck Aune, ${ }^{3}$ and Lehtomäki Leila ${ }^{4}$ \\ ${ }^{1}$ School of Health Sciences (Nursing Science), University of Tampere, Etelä-Pohjanmaa Hospital District, Finland \\ ${ }^{2}$ School of Health Sciences, University of Tampere and Science Center, Pirkanmaa Hospital District, Finland \\ ${ }^{3}$ School of Health Sciences, University of Tampere, National Institute of Health and Welfare, \\ Technologies and Practices Assessment Unit, FinSoc, Finland \\ ${ }^{4}$ The Finnish Union of Public Health Nurses, Finland
}

Correspondence should be addressed to Paavilainen Eija; eija.paavilainen@uta.fi

Received 1 August 2014; Accepted 27 October 2014; Published 19 November 2014

Academic Editor: Kathleen Finlayson

Copyright (C) 2014 Paavilainen Eija et al. This is an open access article distributed under the Creative Commons Attribution License, which permits unrestricted use, distribution, and reproduction in any medium, provided the original work is properly cited.

\begin{abstract}
Objectives. To describe how Finnish public health nurses identify and intervene in child maltreatment and how they implement the National Clinical Guideline in their work. Design and Sample. Cross-sectional survey of 367 public health nurses in Finland. Measures. A web-based questionnaire developed based on the content areas of the guideline: identifying, intervening, and implementing. Results. The respondents reported they identify child maltreatment moderately (mean 3.38), intervene in it better (4.15), and implement the guideline moderately (3.43, scale between 1 and 6). Those with experience of working with maltreated children reported they identify them better $(P<0.001)$, intervene better $(P<0.001)$, and implement the guideline better $(P<0.001)$ than those with no experience. This difference was also found for those who were aware of the guideline, had read it, and participated in training on child maltreatment, as compared to those who were not aware of the guideline, had not read it, or had not participated in such training. Conclusions. The public health nurses worked quite well with children who had experienced maltreatment and families. However, the results point out several developmental targets for increasing training on child maltreatment, for devising recommendations for child maltreatment, and for applying these recommendations systematically in practice.
\end{abstract}

\section{Background}

Child maltreatment is a public health problem and a violation of children's human rights [1]. The latest research in Finland $[2,3]$ shows that children and youth experience a wide range of maltreatment at home-meaning physical, emotional, and sexual violence, neglect, and witnessing violence between parents. The same forms of child maltreatment are observed in other countries in Europe and globally [4-8]. In addition, research attention has been paid to children living in families where intimate partner violence is part of their everyday life $[2,9]$. Although much has been done for discovering the situation of children living in violent homes, effort is still needed for knowing more about identification and prevention practices, for developing them.

Researchers in the child maltreatment field show that child maltreatment within the family has an enormous effect on children and their future physical, emotional, and social welfare, often resulting in inequality and marginalization $[10$, 11]. A meta-analysis on the health consequences [12] stressed that all forms of child maltreatment should be considered important risks to health. Lifelong impairments in learning, behaviour, and both physical and mental health are strongly linked to adverse experiences in childhood. Exposure to child maltreatment can disrupt normal biological and social development, creating a cascade of events that lead to toxic stress which results in changes in the developing nervous, cardiovascular, immune, and metabolic systems which last a lifetime [13]. Awareness of the serious long-term consequences should encourage better identification of those at risk and the development of effective interventions to protect children from violence $[1,14]$. In the UK, the National Institute for Health and Clinical Excellence (NICE) guidance 
was developed to raise healthcare professionals' awareness of the alerting features of child maltreatment [15]. In Finland a guideline has also been written [10] concerning identifying and intervening in child maltreatment, based on a systematic literature review [16]. In the Finnish guideline, the risk factors for the child, the parents, and the family, signs and symptoms, and the principles for identifying them and intervening in child maltreatment are described. The central means of identifying and also intervening in maltreatment include, for example, knowing and evaluating the signs of maltreatment of a child, discussion with their parents about the family situation and relationships within the family, and discussion about child rearing practices, home visits, and multiprofessional practices [10]. The guideline is meant to be a tool for evidence-based practice $[17,18]$, used by public health nurses (PHNs) and in multiprofessional collaboration with other professionals meeting and working with children, adolescents, and families in different settings. In papers evaluating multiprofessional practices, the knowledge exchange concerning the situation of the child and the family is frequently ineffective or not family oriented: professionals may not actively include the family in the collaboration or they do not work intensively enough together (e.g., see $[19,20])$. Identifying and intervening in families' high-risk situations and child maltreatment is not as evidence-based as it could be.

PHNs, as healthcare workers who meet almost all children and their families at clinics, schools, and homes, are key persons in identifying, preventing, and intervening in child maltreatment. In Finland PHNs provide care for children and families across a wide age range, from maternity care and preschool to school-aged children, and in many different settings including clinics, clients' homes, and schools. Before school age (age 7 in Finland), children and their families visit child health clinics at least 16 times and, once in school, children and young people will see a PHN at least once a year. These services are free for all families and almost all families use them [21].

The objective of the current research was to describe how Finnish PHNs identify and intervene in child maltreatment and how they implement the clinical guideline concerning these issues in their work. Findings can be used for the development of identification and intervention practices and education.

\section{Research Questions}

This study was designed to address the following research questions.

(1) How do PHNs identify child maltreatment?

(2) How do they intervene in child maltreatment?

(3) How do they describe their implementation possibilities concerning identifying and intervening in child maltreatment?

(4) What are the background factors that promote identification, intervention, and implementation?

\section{Methods}

3.1. Design and Sample. The respondents to the current survey were recruited from the register of the Finnish Union of Public Health Nurses, in 2012. All the members who had an email address and appeared to have worked in child-related clinics $(n=800)$ were sent the electronic questionnaire in February 2012 and were reminded after two weeks. The board of the union gave the ethical approval and research permission. Completing the survey indicated informed consent and no identifiers were collected [22]. In the letter attached to the questionnaire, it was stated that the permission for the research was clear, the results will be published anonymously and filling in the questionnaire was interpreted as participation in the study. Altogether 367 PHNs answered the survey, resulting in the response rate of $46 \%$.

3.2. Measures. The survey instrument was developed for this study, and its content was based on the National Clinical Guideline concerning identifying and intervening in child maltreatment and implementing the guidelines on this topic $[10,16]$. It included five background questions (gender, age, work experience, present job and location, and work experience in cities/countryside/both) and three questions concerning whether they knew that guidelines existed and, if so, whether they had read them and whether they had been trained on the topic. They were also asked how many child maltreatment cases they had encountered or suspected, during the previous six months. The survey instrument consisted in Likert Scale statements ( $6=$ totally agree, $1=$ totally disagree) divided under three sum variables: identifying ( 8 statements), intervening (31 statements), and implementing (8 statements). The instrument was developed by the group of researchers $(n=12)$ who were experts in child maltreatment issues and/or statistical methods. The instrument was pilot tested by sending the electronic version to ten PHNs who completed the questionnaire. Modifications were made based on their responses.

3.3. Data Analysis. The means and standard deviations (SDs) or percentage distributions were calculated for all demographic variables. Responses for nurses' perceptions of how they identify and intervene in child maltreatment and how they implement the guidelines were divided into groups: disagree (responses of 1-3) and agree (responses 4-6). These three variables were also combined as sum variables, identifying (Cronbach's Alpha 0.866), intervening (0.957), and implementing (0.854), showing solid reliability [23]. Differences between groups according to demographics were tested using Pearson correlations, $t$-tests, and ANOVA. Linear regression analysis was also done to see which factors explain identifying, intervening, and implementing. Having worked at maternity and family planning, child health clinic, school health, and all other places were used as separate independent binary variables in the model, together with suspicion of maltreatment (or actual meeting of maltreated children) and working years. 
TABLE 1: Background information concerning the participants $(N=367)$.

\begin{tabular}{lr}
\hline Variables & Mean (SD) \\
\hline $\begin{array}{l}\text { Age in years } \\
\text { Working years as a nurse }\end{array}$ & $42,5(10,8)$ \\
& $12,3(9,9)$ \\
\hline & Percentages \\
\hline Working in urban areas/countryside/both & $65,9 / 26,7 / 7,4$ \\
Knowledge of the existence of a guideline (yes/no)? & $77,1 / 22,9$ \\
Had they read the guideline (yes/no)? & $46,3 / 53,7$ \\
Had they had education on the topic (within a year/earlier/never)? & $11,2 / 34,6 / 54,2$ \\
How many (0/1-4/5 or more//missing) child maltreatment cases they had met during six months? & $36,8 / 19,9 / 4,6 / / 38,7$ \\
How many (0/1-4/5 or more//missing) suspected child maltreatment cases they had met during six months? & $28,3 / 35,7 / 6,5 / / 29,4$ \\
\hline
\end{tabular}

\section{Results}

4.1. Demographic Characteristics. Almost all of the respondents $(N=367)$ were women (there were only two men), with a mean age of 42 (ranging from 23 to 64) and a mean working career of 12 years (ranging from 0 to 37 years). Thirty eight percent of them worked in family planning and maternity, $45 \%$ in a child welfare clinic, $30 \%$ in school health, and $48 \%$ in other clinics, for instance in student health care clinics or clinics for adults. The respondents may work in several clinics; for instance 107 respondents worked in both maternity and child welfare clinics. Seventy-seven percent knew that there was a guideline, $46 \%$ reported they had read it, and $46 \%$ had participated in training on the topic. During the previous six months, $37 \%$ of the respondents reported they had not met maltreated children, $20 \%$ had met $1-4$ maltreated children, and 5\% had met five or more maltreated children, to the best of their knowledge. Correspondingly, $28 \%$ reported they had not suspected any maltreatment cases, $36 \%$ had suspected that 1-4 children they encountered had been maltreated, and $7 \%$ had suspected that five or more children had been maltreated (Table 1).

4.2. Identifying Child Maltreatment. The PHNs agreed they were able to identify maltreated children moderately well (mean 3.38, SD 0.84). Only 43\% agreed the child's behaviour was a factor in identifying child maltreatment, and $37 \%$ agreed that the parents' behaviour was a factor. Fifty-four percent agreed that physical signs were a factor and $44 \%$ agreed that psychological signs were a factor. Only $15 \%$ of the PHNs meet maltreated children often, according to their own evaluation (Table 2).

4.3. Intervening in Child Maltreatment. Intervening in child maltreatment was easier for the respondents (mean 4.15, SD 0.91 ) than identifying it (mean 3.38). Most (80\%) respondents felt they discussed everyday problems and problems in the child's development adequately (80\%) and that they advised the parents to seek help when they need it (88\%). On the other hand, the respondents reported that couple's relationship problems are discussed less often (52\%). The respondents thought they helped the maltreated child (52\%) and the family (50\%) sufficiently well. Fifty-nine percent thought that multiprofessional collaboration was working well in their
TABLE 2: Items included in identifying sum variable and the percentages that agree/disagree $(N=367)$.

\begin{tabular}{lc}
\hline Identifying & $\begin{array}{c}\text { agree } 4-6 / \text { disagree } \\
1-3)\end{array}$ \\
\hline PHNs meet maltreated children often & $15 / 85 \%$ \\
PHNs recognize child maltreatment based on & \\
Child-related risk factors & $53 / 47 \%$ \\
Risk factors related to parents & $66 / 34 \%$ \\
Family-related risk factors & $67 / 33 \%$ \\
The child's behavior & $43 / 57 \%$ \\
The parents' behavior & $37 / 63 \%$ \\
PHNs recognize physical signs sufficiently well & $54 / 46 \%$ \\
PHN's recognize mental signs sufficiently well & $44 / 56 \%$ \\
\hline
\end{tabular}

municipality, and $50 \%$ of them receive enough support for multiprofessional collaboration from their superiors. Fiftyfour percent of the respondents have joint guidelines for child maltreatment cases, and 65\% have clear instructions on how to make a report to child protection authorities (Table 3).

4.4. Implementing the Clinical Guideline. PHNs reported they implemented the recommendations written in the guideline moderately (mean 3.43, SD 1.01). Among the respondents, $87 \%$ considered the guidelines important. The guideline for child maltreatment guides the work of $57 \%$ of the respondents, and $87 \%$ reported they will gladly adjust their work practices according to the guideline. Of the respondents, $21 \%$ had received enough training regarding the guideline and $44 \%$ had studied the content of the guideline independently. Twenty-three percent of the respondents had discussed the guideline at their workplace, $44 \%$ supported each other in actions following the guideline, and 38\% thought that their workplace had sufficient resources for acting according to the guideline.

4.5. Factors Promoting Identifying, Intervening, and Implementing. PHNs who had met maltreated children reported they were able to identify child maltreatment better than those without that experience, according to their own evaluation (mean 3.79 versus 3.07, $P<0.001$ ). They also intervened in child maltreatment cases better (mean 4.48 versus 3.88 , 
TABLE 3: Items included in intervening sum variable and the percentages that agree/disagree $(N=367)$.

\begin{tabular}{|c|c|}
\hline Intervening & (agree 4-6/disagree 1-3) \\
\hline \multicolumn{2}{|l|}{ PHNs discuss sufficiently well with families about } \\
\hline Risk factors in families & $61 / 39 \%$ \\
\hline Child rearing practices & $69 / 31 \%$ \\
\hline Problems in the couple's relationship & $52 / 48 \%$ \\
\hline Problems in everyday life & $80 / 20 \%$ \\
\hline Child development & $80 / 20 \%$ \\
\hline Problems in child development & $79 / 21 \%$ \\
\hline \multicolumn{2}{|l|}{ PHNs advice parents sufficiently well to } \\
\hline Seek help when needed & $88 / 12 \%$ \\
\hline Act well in situations when the child has a tantrum & $76 / 24 \%$ \\
\hline Act well when the child behaves badly & $71 / 29 \%$ \\
\hline Act well when the child does not fulfill expectations & $60 / 40 \%$ \\
\hline Act well when the child has special needs or is ill & $69 / 31 \%$ \\
\hline Act well when the child cries & $76 / 24 \%$ \\
\hline Discuss their joint child rearing practices & $67 / 33 \%$ \\
\hline \multicolumn{2}{|l|}{ When suspecting child maltreatment, PHN } \\
\hline Asks about it straightforwardly & $69 / 31 \%$ \\
\hline Always makes a child welfare notification & $86 / 14 \%$ \\
\hline Helps the maltreated child sufficiently well & $52 / 48 \%$ \\
\hline Helps the family sufficiently well & $50 / 50 \%$ \\
\hline Documents maltreatment sufficiently well & $82 / 18 \%$ \\
\hline Guides to follow-up treatment sufficiently well & $81 / 19 \%$ \\
\hline Listens to the family under suspicion sufficiently well & $83 / 17 \%$ \\
\hline Collaborates sufficiently well with other professionals & $86 / 14 \%$ \\
\hline Thinks multiprofessional collaboration works well in the municipality & $59 / 41 \%$ \\
\hline Thinks multiprofessional collaboration works well in their organization & $69 / 31 \%$ \\
\hline Knows who to contact when suspecting child maltreatment & $87 / 13 \%$ \\
\hline \multicolumn{2}{|l|}{ When suspecting child maltreatment PHN gets enough support from } \\
\hline Superiors & $50 / 50 \%$ \\
\hline Peers & $82 / 18 \%$ \\
\hline The clinic physician & $69 / 31 \%$ \\
\hline Child protection & $69 / 31 \%$ \\
\hline \multicolumn{2}{|l|}{ In our clinic: } \\
\hline We have joint instructions to handle child maltreatment cases & $54 / 46 \%$ \\
\hline We have clear instructions on how to make a child welfare notification & $65 / 35 \%$ \\
\hline It is possible to work according to the child maltreatment guideline & $59 / 41 \%$ \\
\hline
\end{tabular}

$P<0.001)$ and implemented the recommendations of the guideline better (mean 3.79 versus $3.16, P<0.001$ ). The same applied to nurses who were aware of the guideline, had read it, and participated in training on recognizing and intervening in child maltreatment (Table 4).

According to the regression analysis, with working years and suspicion of maltreatment as additional independent variables, those working as school health nurses were able to identify cases better than others. In addition, those working as school health nurses or at child welfare clinics also intervened better than others. Those working at family planning or maternity clinics implemented the guideline better than others. Those who had suspected child maltreatment obviously had better identification, intervention, and implementation than those who had not suspected child maltreatment (Table 5).

According to the regression analysis, with working years and actual contact with maltreated children as additional independent variables, only intervention was at a higher level (for those who worked as school health nurses) compared to others. Those who had met maltreated children obviously had better identification, intervention, and implementation than those who had not met maltreated children.

\section{Discussion}

The PHNs identified child maltreatment to a moderate degree. They thought that they identified risk factors related 
TABLE 4: The effects of separate background factors on identifying, intervening, and implementing.

\begin{tabular}{|c|c|c|c|}
\hline Variables & Identifying & Intervening & Implementing \\
\hline Age (correlation, significance) & $0,01 \mathrm{NS}$ & $0,01 \mathrm{NS}$ & $0,14^{* *}$ \\
\hline Working years as a nurse (correlation, significance) & $-0,02 \mathrm{NS}$ & $-0,03 \mathrm{NS}$ & $0,07 \mathrm{NS}$ \\
\hline Working in urban areas/countryside/both (ANOVA sig.) & NS & NS & NS \\
\hline Knowledge of the existence of a guideline ( $t$-test sig.) & $* * *$ & $* * *$ & $* * *$ \\
\hline PHN had read the guideline ( $t$-test sig.) & $* * *$ & $* * *$ & $* * *$ \\
\hline PHN had had education on the topic (ANOVA sig.) & * & $* * *$ & $* * *$ \\
\hline $\begin{array}{l}\text { How many }(0,1-4,5 \text {, or more) child maltreatment cases they had met during six } \\
\text { months (ANOVA sig.) }\end{array}$ & $* * *$ & $* * *$ & $* * *$ \\
\hline $\begin{array}{l}\text { How many }(0,1-4,5 \text { or more) suspected child maltreatment cases they had met } \\
\text { during six months (ANOVA sig.) }\end{array}$ & $* * *$ & $* * *$ & $* * *$ \\
\hline
\end{tabular}

Estimate significance $\left(P\right.$ value): NS $=$ not significant; ${ }^{*}<0,05 ;{ }^{* *}<0,01 ;{ }^{* * *}<0,001$.

TABLE 5: Estimated unstandardized regression coefficients for all variables from linear regression models, separately for identifying, intervening, and implementing $(N=367)$.

\begin{tabular}{lccc}
\hline Model variables & Identifying & Intervening & Implementing \\
\hline Have worked in: maternity and family planning & 0,075 & 0,127 & 0,296 \\
Have worked at: a Child Health Clinic & $-0,103$ & 0,325 & 0,309 \\
Have worked at: a School Health Clinic & 0,216 & $0,301^{*}$ & $-0,381^{*}$ \\
Have worked at: other places & 0,086 & $-0,003$ & 0,133 \\
Working years & 0,000 & $0,390^{* *}$ & 0,044 \\
Had met maltreatment cases (yes/no) & $0,658^{* * *}$ & 0,227 & $0,583^{* * *}$ \\
\hline Have worked in: maternity and family planning & $-0,058$ & $0,344^{*}$ \\
Have worked at: a Child Health Clinic & $-0,008$ & $0,309^{*}$ & 0,096 \\
Have worked at: a School Health Clinic & $0,293^{*}$ & $0,316^{* *}$ & $-0,106$ \\
Have worked at: other places & $-0,038$ & $-0,317^{* *}$ & $0,015^{*}$ \\
Working years & $-0,005$ & 0,000 & $0,310^{*}$ \\
Had suspected maltreatment cases (yes/no) & $0,507^{* * *}$ & $0,322^{* *}$ &
\end{tabular}

Estimate significance $(P$ value $):{ }^{*}<0,05 ;{ }^{* *}<0,01 ;{ }^{* * *}<0,001$.

to the child, parents, or the family the best and issues related to the child's or the parents' behavior the worst. They identified signs of physical and emotional abuse better. Similar results have also been reported in a survey for hospital staff [24]. Different forms of child maltreatment are identified at different levels: signs of physical maltreatment are often clearer than, for example, signs of emotional maltreatment or neglect.

The respondents thought that they can intervene in maltreatment better than they can identify it. They discussed both everyday issues and problems related to child development with the parents at a child health center, but they failed to discuss relationship issues sufficiently. These results also agree with earlier results [9, 25-27].

When suspecting that a child has been maltreated, the respondents asked about it directly, made a child protection report, and documented the event in the child's documentation. In their opinion, however, they felt that they were not able to provide enough help for the child and the family in the situation. According to our regression models, those nurses working at schools assessed their child maltreatment identification practices more positively than those working at other places. This may be because children's behavior or problems in school attendance may more likely lead to discussions about the child's situation than at a child welfare clinic. At clinic children are younger and do not express being ill so clearly. At family planning or maternity clinics nurses implemented the guideline very well at a knowledge level and were willing to use this knowledge. However, at the identifying and intervening levels, they were not able to apply their willingness in real situations. According to earlier studies $[9,25,27]$, PHNs feel that they are in a good position to take the actions needed but they need more training on applying their knowledge in real situations when working with children and families.

According to the PHNs, multiprofessional collaboration is not working very well in the municipality or organization where they work. Common guidelines on how to act on child maltreatment suspicions or how to make a child protection report were not used often enough. Some of the results may seem to be confusing, for example, concerning agreeing on the importance of the guidelines even when not knowing them very well. This may be due to the fact that the respondents agree that identification and intervening are important but they do not know well enough what to do and how to implement their knowledge into multiprofessional 
work. According to Lehtomäki [17], the attitudes towards care guidelines in general are positive but applying them requires support and administrative effort from their superiors and development of joint practices. In this study, the respondents rated themselves as not receiving enough support from their superiors or child protection authorities. According also to Yagasaki and Komatsu [28], guidelines are regarded as important; however they are not fully applied into practice. To be successful in applying any research-based guidelines, organizational, administrational, multidisciplinary, and individual barriers have to be challenged by a strategy that gives tools for effective implementation.

PHNs who had met maltreated children or who had participated in training on child maltreatment were able to identify maltreatment and they intervened in it better than those who had not met such children or participated in such training. Earlier studies have also gained similar results. According to Paavilainen et al. [24], nurses who have participated in training or who have met maltreated children find identification and intervention even more difficult than nurses who have not encountered these issues at all. Based on this, it is possible that nurses who have explored the issue and acted on it have a more profound understanding of how difficult and complex the issue is. Also, when asking about these difficult issues with a cross-sectional design as we did in our study, using a self-reported questionnaire might also be a limitation. However, it seems that PHNs did not over estimate their capability in identifying or intervening and many developmental challenges can be presented based on the results.

\subsection{Implications for Nursing Practice. PHNs are generally} aware that identification of and intervention in child maltreatment are an important part of their job (see also [25]). However, the lack of effort in creating common guidelines and practices and ensuring the functionality of multiprofessional collaboration were weaknesses in practical work and actions [19]. This is a question of work organization and management and also of focusing on activities that are really helpful and effective for children and families. PHNs are in a position to take a leadership role in the prevention of child maltreatment as well as addressing the system barriers such as knowledge exchange challenges or coordination within multiprofessional activities. This will lead to supporting families before risks of maltreatment are realized into actual maltreatment in families. Solving or treating child maltreatment cases is the responsibility of many administratively separate units: child health centers, hospitals, at day care, and in child protection. The managers of these units should ensure that collaboration, in both prevention and treatment levels, can work across administrative boundaries. This kind of development can be done globally, based on international research evidence and on the service system of children and families in each country.

5.2. Implications for Nursing Education. More attention should be paid to training on child maltreatment in the basic and complementary education of PHNs. This training should include the topics of high risk family environments (identifying and discussing them), discussing the everyday issues and problems of families, the risks and manifestations of maltreatment, the identifying symptoms and signs, and the concrete means and methods to identify and intervene in maltreatment. There should also be training on issues regarding multiprofessional collaboration and legislation. The service system and legislation concerning children and families differ in each country; this has of course to be considered. However, the health, well-being, and needs of children are global issues and can be used as the basis of education.

5.3. Implications for Nursing Research. These results show well the situation concerning the identification of and intervention in child maltreatment by PHNs and how they implement the guideline concerning these issues in their work with children and families. Further knowledge is needed, for example, on how to provide education on these issues and change PHNs practices. This could be done by a followup study with an educational intervention. Also, comparable data from other countries would be interesting and important, providing knowledge of the situation in different countries. This study is already in process, and there is already data from Japan collected with the same instrument.

\section{Conclusion}

The primary prevention of child maltreatment is the most important issue from the perspectives of children, families, and the whole society, in Finland and globally, although also secondary and tertiary prevention are very crucial to development. In aiming to prevent child maltreatment and increase the well-being of children, guidelines and risk assessment practices for PHNs and supportive interventions for families with child maltreatment risk should be developed and evaluated. This can be done by using guidelines for creating effective interventions and evaluating the process and outcomes by follow up research.

\section{Conflict of Interests}

There is no conflict of interests.

\section{References}

[1] R. Reading, S. Bissell, J. Goldhagen et al., "Promotion of children's rights and prevention of child maltreatment," The Lancet, vol. 373, no. 9660, pp. 332-343, 2009.

[2] S. Lepistö, T. Luukkaala, and E. Paavilainen, "Witnessing and experiencing domestic violence: a descriptive study of adolescents," Scandinavian Journal of Caring Sciences, vol. 25, no. 1, pp. 70-80, 2011.

[3] N. Ellonen, J. Kääriäinen, V. Salmi, and H. Sariola, "Lasten ja nuorten väkivaltakokemukset (child victim survey: violence against children in Finland)," Poliisiammattikorkeakoulun Raportteja 71/2008, Poliisiammattikorkeakoulun, Tampere, Finland, 2008.

[4] R. Gilbert, A. Kemp, J. Thoburn et al., "Recognising and responding to child maltreatment," The Lancet, vol. 373, no. 9658, pp. 167-180, 2009. 
[5] K. Helweg-Larsen, N. Schutt, and H. Larsen, Unger trivsel År 2008, 2009, http://www.si-folkesundhed.dk/upload/samlet_ rapport_unges_trivsel.pdf.

[6] R. Ueda, Y. Yasuda, and K. Maeda, "Child-rearing behaviour for pre-school children at $\mathrm{M}$ city in Japan in relation to the prevention of child maltreatment: similarities and differences between 1984-2006," Japanese Journal of Health \& Human Ecology, vol. 74, pp. 99-113, 2008.

[7] P. Cawson, C. Wattam, S. Brooker, and E. Kelly, Child Maltreatment in the United Kingdom: A Study of the Prevalence of Child Abuse and Neglect, NSPCC, London, UK, 2000.

[8] M. A. Straus and J. H. Stewart, "Corporal punishment by American parents: national data on prevalence, chronicity, severity, and duration, in relation to child and family characteristics," Clinical Child and Family Psychology Review, vol. 2, no. 2, pp. 55-70, 1999.

[9] D. M. Davidov, S. M. Jack, S. S. Frost, and J. H. Coben, "Mandatory reporting in the context of home visitation programs: intimate partner violence and children's exposure to intimate partner violence," Violence Against Women, vol. 18, no. 5, pp. 595-610, 2012.

[10] E. Paavilainen and A. Flinck, "Identification of and intervention in child maltreatment," in A National Clinical Practice Guideline, Nursing Research Foundation, 2008, http://www.hotus.fi/.

[11] R. Tenney-Soeiro and C. Wilson, "An update on child abuse and neglect," Current Opinion in Pediatrics, vol. 16, no. 2, pp. 233237, 2004.

[12] R. E. Norman, M. Byambaa, R. De, A. Butchart, J. Scott, and T. Vos, "The long-term health consequences of child physical abuse, emotional abuse, and neglect: a systematic review and meta-analysis," PLoS Medicine, vol. 9, no. 11, Article ID e1001349, 2012.

[13] A. Garner, J. Shonkoff, B. Siegel et al., "Early childhood adversity, toxic stress, and the role of the pediatrician: translating developmental science into lifelong health," Pediatrics, vol. 129, no. 1, pp. e224-e231, 2012.

[14] H. MacMillan, N. Wathen, J. Barlow, D. Fergusson, J. Leventhal, and $\mathrm{H}$. Taussig, "Interventions to prevent child maltreatment and associated impairment," The Lancet, vol. 373, no. 9659, pp. 250-266, 2009.

[15] J. V. Appleton and D. Glaser, "Suspecting child maltreatment," Community Practitioner, vol. 82, no. 9, pp. 34-35, 2009.

[16] E. Paavilainen and A. Flinck, "National clinical nursing guideline for identifying and intervening in child maltreatment within the family in Finland," Child Abuse Review, vol. 22, no. 3, pp. 209-220, 2013.

[17] L. Lehtomäki, "The implementation of national guidelines in health centers," Acta Electronica Universitatis Tamperensis, vol. 856, 2009, http://acta.uta.fi.

[18] A. Qaseem, F. Forland, F. Macbeth, G. Ollenschläger, S. Phillips, and P. van der Wees, "Guidelines international network: toward international standards for clinical practice guidelines," Annals of Internal Medicine, vol. 156, no. 7, pp. 525-531, 2012.

[19] H. Cass, "Child protection: a blend of art and science," Archives of Disease in Childhood, vol. 99, no. 2, pp. 101-102, 2014.

[20] Ministry of Interior, 2014, Investigation concerning children's deaths, http://www.turvallisuustutkinta.fi/fi/index/ajankohtaista/aloitetuttutkinnattiedotteet/y2012-sllastenkuolemat .html.
[21] Ministry of Social Affairs and Health, Child and Family Policy in Finland, Brochures 9eng, 2013, http://www.stm.fi/c/document_library/get_file?folderId=6511570\&name=DLFE-25916 .pdf.

[22] E. Paavilainen, S. Lepistö, and A. Flinck, "Ethical issues in family violence research in healthcare settings," Nursing Ethics, vol. 21, no. 1, pp. 43-52, 2014.

[23] N. Burns and S. Grove, The Practice of Nursing Research, Saunders, Philadelphia, Pa, USA, 2008.

[24] E. Paavilainen, J. Merikanto, P. Åstedt-Kurki, P. Laippala, T. Tammentie, and M. Paunonen-Ilmonen, "Identification of child maltreatment while caring for them in a university hospital," International Journal of Nursing Studies, vol. 39, no. 3, pp. 287294, 2002.

[25] A. Lazenbatt and R. Freeman, "Recognizing and reporting child physical abuse: a survey of primary healthcare professionals," Journal of Advanced Nursing, vol. 56, no. 3, pp. 227-236, 2006.

[26] N. Stanley, "Reasserting the roles of relationships, empathy and training in child protections," Child Abuse Review, vol. 19, pp. 303-307, 2010.

[27] D. M. Davidov, M. R. Nadorff, S. M. Jack, and J. H. Coben, "Nurse home visitors' perspectives of mandatory reporting of children's exposure to intimate partner violence to child protection agencies," Public Health Nursing, vol. 29, no. 5, pp. 412-423, 2012.

[28] K. Yagasaki and H. Komatsu, "Preconditions for successful guideline implementation: perceptions of oncology nurses," BMC Nursing, vol. 10, article 23, 2011. 


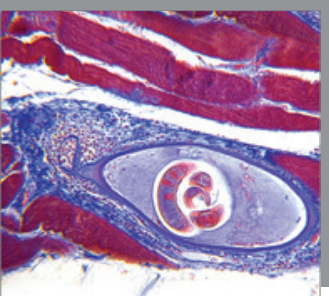

Gastroenterology

Research and Practice
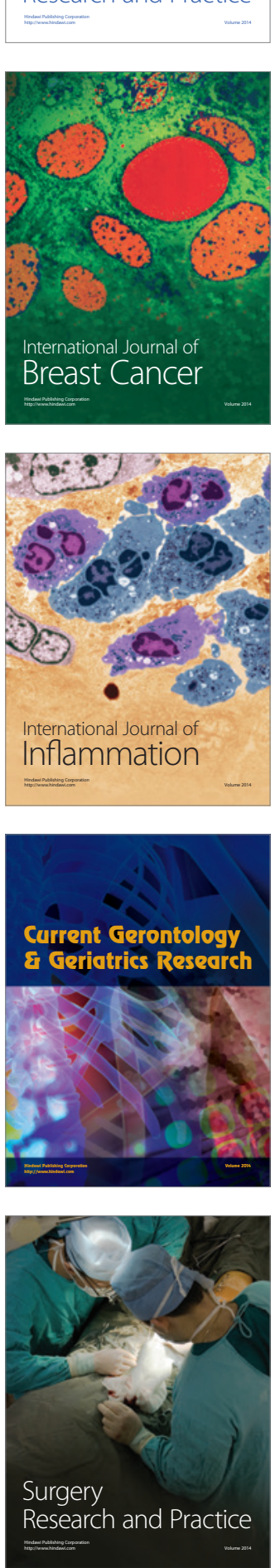

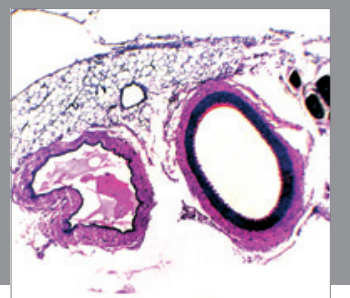

International Journal of Hypertension
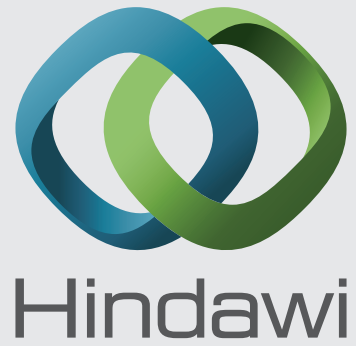

Submit your manuscripts at http://www.hindawi.com
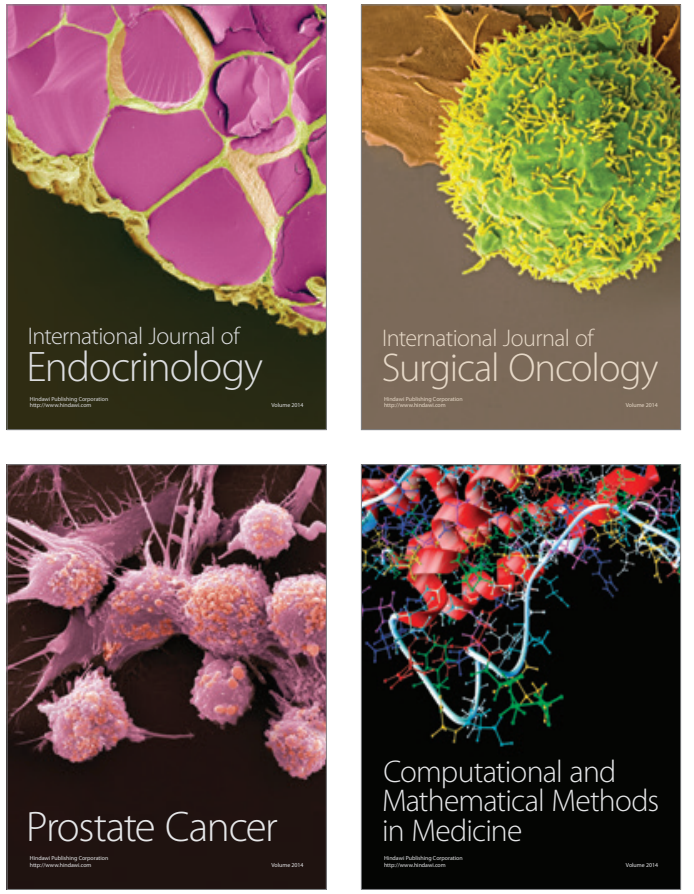
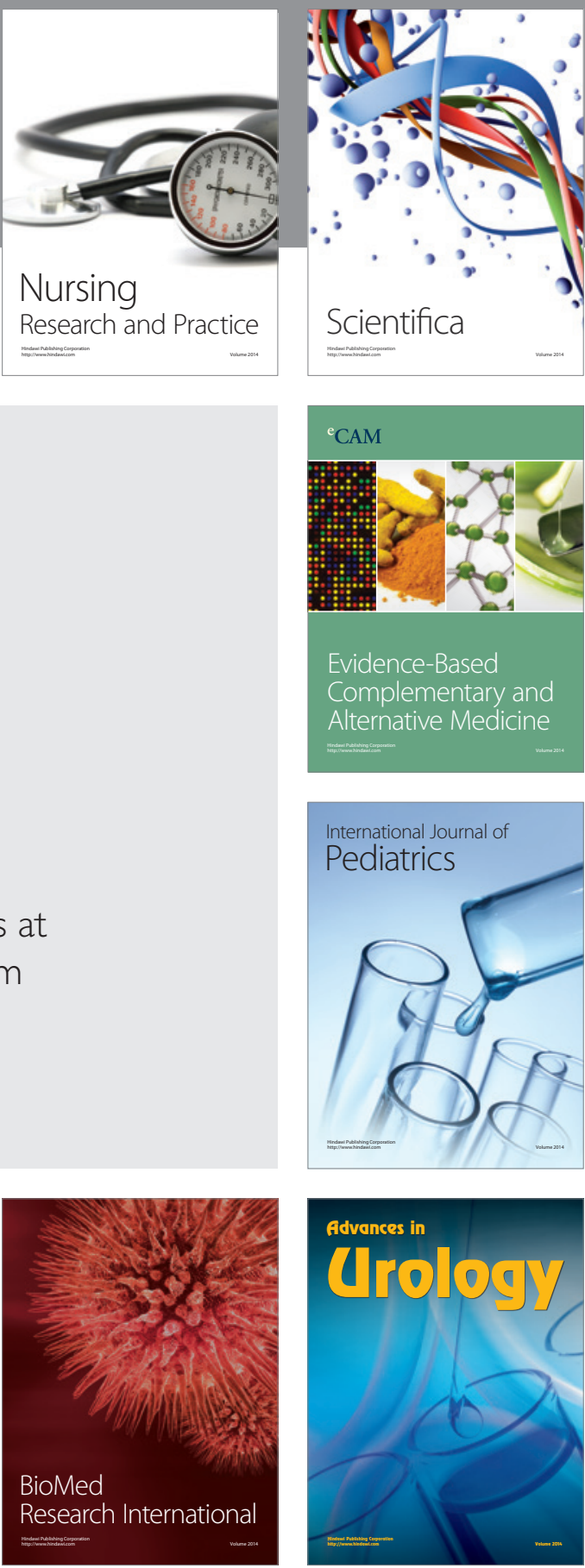

Nursing

Research and Practice

Scientifica

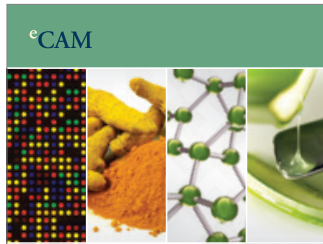

Evidence-Based

Complementary and Alternative Medicine
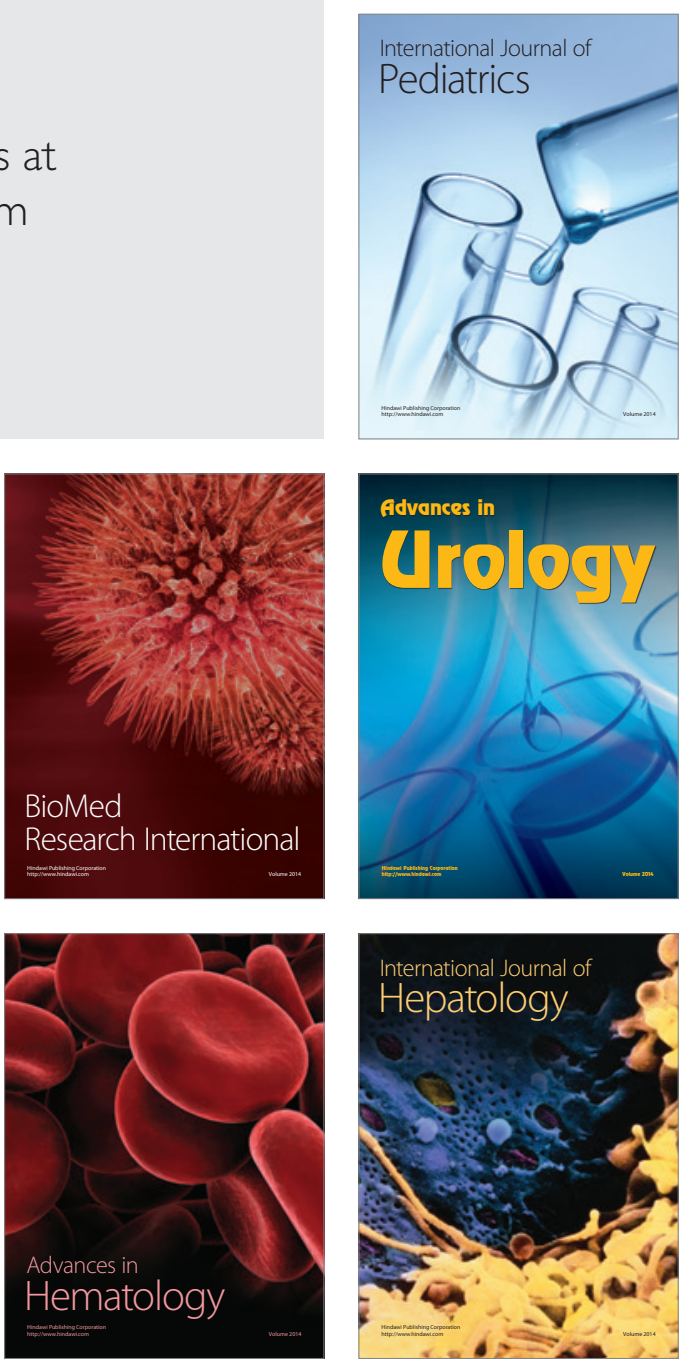